\title{
Application of Jute Fiber for the Improvement of Subgrade Characteristics
}

\author{
Md. Akhtar Hossain*, Md. Shakhawat Hossain, Md. Kamrul Hasan \\ Department of Civil Engineering, Rajshahi University of Engineering \& Technology, Rajshahi, Bangladesh
}

Email address:

akhtar412002@yahoo.com (Md. A. Hossain), shakhawat09ruet@gmail.com (Md. S. Hossain), hasankamrul.ce@gmail.com (Md. K. Hasan)

To cite this article:

Md. Akhtar Hossain, Md. Shakhawat Hossain, Md. Kamrul Hasan. Application of Jute Fiber for the Improvement of Subgrade

Characteristics. American Journal of Civil Engineering. Vol. 3, No. 2, 2015, pp. 26-30. doi: 10.11648/j.ajce.20150302.11

\begin{abstract}
Improvement in subgrade has always been an area of concern to highway and geotechnical engineers. In case of a highway, a weak subgrade results in greater thickness of pavement layer which increases the cost of pavement construction. To strengthen the subgrade soil, the use of jute fiber is advantageous because they are cheap, locally available, biodegradable, and eco-friendly. Jute fiber mixed randomly with subgrade soil has significant impact on the improvement of subgrade characteristics over the last decade. Keeping this in view an experimental study was conducted on locally available soil reinforced with jute fiber. In this study the soil samples were prepared at its maximum dry density corresponding to optimum moisture content in the CBR mold with and without reinforcement. The percentage of jute fiber by dry weight of soil was taken as $0.3 \%, 0.6 \%, 0.9 \%$, and $1.2 \%$. In the present investigation the length of fiber was taken as $15 \mathrm{~mm}$ and $30 \mathrm{~mm}$, and two different diameters $(4 \mathrm{~mm}$ and $8 \mathrm{~mm})$ were considered for each fiber length. From the laboratory tests the effect of jute fiber content on density of soil (optimum moisture content and maximum dry density) was observed for each length and diameter of jute fiber. It was observed that the optimum moisture content increases and the maximum dry density decreases with the increase in jute fiber content for each length and diameter of jute fiber. The laboratory CBR values of soil and soil reinforced with fiber were determined. The effects of aspect ratio (length/diameter ratio) of jute fiber on CBR value of soil were also investigated. Test results indicate that CBR value of soil increases with the increase in length of jute fiber. It was also observed that increasing the diameter of jute fiber further increases the CBR value of reinforced soil, and this increase is substantial at fiber content of $1.2 \%$ for aspect ratio of 3.75 (length $=30 \mathrm{~mm}$, diameter $=8 \mathrm{~mm}$ ).
\end{abstract}

Keywords: Subgrade, Jute Fiber, Length, Diameter, CBR Value

\section{Introduction}

Transportation plays a vital rule in the development of economy, industry, society and culture of any country. To achieve development in those fields, a satisfactory mode of transport and communication is indispensable. This can be achieved through a transportation system, which is economically viable. Economy in road network can be achieved through economical pavement design. Practically it is not possible to have good subgrade always. Poor subgrade necessitates a greater pavement thickness resulting in increased construction cost. With the aim of reducing pavement thickness on poor subgrade new techniques of construction and soil stabilization have been continuously explored. Poor natural soils make them practically unsuitable for many civil engineering construction activities including road pavements. In such cases natural soils are being treated with different kinds of materials to improve their engineering properties. Aggarwal and Sharma (2010) studied the application of jute fiber in the improvement of subgrade characteristics. From this study it was concluded that jute fiber reinforcement reduces the maximum dry density and increases the optimum moisture content of the subgrade soil. The CBR value of the subgrade soil increases up to $250 \%$ with the inclusion of bitumen coated jute fiber [1]. Fiber reinforced soil has been used in many countries in the recent past and further research is in progress for many hidden aspects of it. Fiber reinforced soil is effective in all types of soil (i.e. sand, silt, clay). Use of natural material such as jute, coir, sisal and bamboo, as reinforcing materials in soil is prevalent for a long time and they are abundantly used in many countries like India, Philippines, and Bangladesh etc. The main advantage of these materials is they are locally available and are very cheap. They are biodegradable hence do not create disposal problem in environment. Processing of 
these materials into a usable form is an employment generation activity in rural areas of these countries. If these materials are used effectively, the rural economy can get uplift and also the cost of construction can be reduced, if the material use leads to beneficial effects in engineering construction. Singh and Bagra (2013) studied the application of jute fiber for the improvement of subgrade soil. They concluded that the CBR value of subgrade soil increases with the increase in jute fiber content. They also conclude that the CBR value also increases with increase in length and diameter of jute thread [2]. Tera et al. (2011) proposed that of all the natural fiber jute has highest tensile strength and withstand rotting and heat [3]. Gray and Ohashi (1983) conducted a series of direct shear tests on dry sand reinforced with different synthetic, natural and metallic fiber to evaluate the effects of parameters such as fiber orientation, fiber content, fiber area ratios, and fiber stiffness on contribution to shear strength [4]. We have several examples of reinforcing the soil like Great Wall of China (earliest example of reinforced earth using branches of trees as tensile materials), Ziggurats of Babylon (woven mats of read were used) etc. In USA \& Europe, the erosion \& stability of slopes for highway and railway embankment is controlled using reinforced soil [5]. Singh (2011) studied the strength characteristics of soil by using Geosynthetic [6]. Sivakumar and Vasudevan (2008) studied the strength and stiffness response of soil reinforced with coir-fiber [7]. Singh (2012) used the coir fiber to improve the laboratory CBR value of soil [8]. Sharma et al. (2011) studied the strength characteristics of soil reinforced with coir fiber [9]. Lawton et al. (1993) used multioriented geosynthetic to improve the laboratory CBR value of soil [10]. Consoli et al. (2002) used plastic waste to improve the engineering behavior of soil [11]. Ranjan et al. (1996) studied the probabilistic analysis of soil mixed randomly with fiber [12]. Rao et al. (2006) studied the behavior of load deformation of fiber reinforced gravel beds overlying soft clay [13]. Michalowski et al. (2002) studied the strength anisotropy of sand reinforced with fiber [14]. Gray et al. (1986) studied the comparative behavior of sand with fabric reinforcement and fiber reinforcement [15].

This paper presents the influence of jute fiber on the CBR value of the studied soil. A number of CBR value tests have been conducted on soil, and soil reinforced with varying amount of jute fiber. The effects of aspect ratio (length/diameter ratio) of jute fiber on CBR value of reinforced soil have also been investigated. The laboratory test results of reinforced and unreinforced soils were also compared.

\section{Material Used}

The soil used in this study is collected from Rajapur of Chapai Nawabgonj district, Bangladesh. The soil sample was collected from a depth of $60 \mathrm{~cm}$ after removing the top surface soil from natural ground surface. The jute fibers used in this study was purchased from the market in the diameter of $4 \mathrm{~mm}$ and $8 \mathrm{~mm}$ and in the length of $15 \mathrm{~mm}$ and $30 \mathrm{~mm}$.
The fiber was coated with bituminous layer in order to protect it from decay. The bitumen used for the coating of jute fiber was of 80-100 grades.

The materials used for the present study are soil, jute fiber, and bitumen.

\subsection{Soil}

Index properties of the soil were determined (Table 1) and classification of soil was done as per Textural Classification. The soil is classified as Clay Loam.

Table 1. Index properties of soil.

\begin{tabular}{ll}
\hline Natural Water Content (\%) & 9.35 \\
Liquid Limit (\%) & 24.82 \\
Plastic Limit (\%) & 17.87 \\
Plasticity Index (\%) & 6.95 \\
Maximum Dry Density (gm./cc) & 1.96 \\
Optimum Moisture Content (\%) & 11.11 \\
Specific Gravity (Gs) & 2.68 \\
CBR (at 2.5 mm) (\%) & 5.22 \\
\hline
\end{tabular}

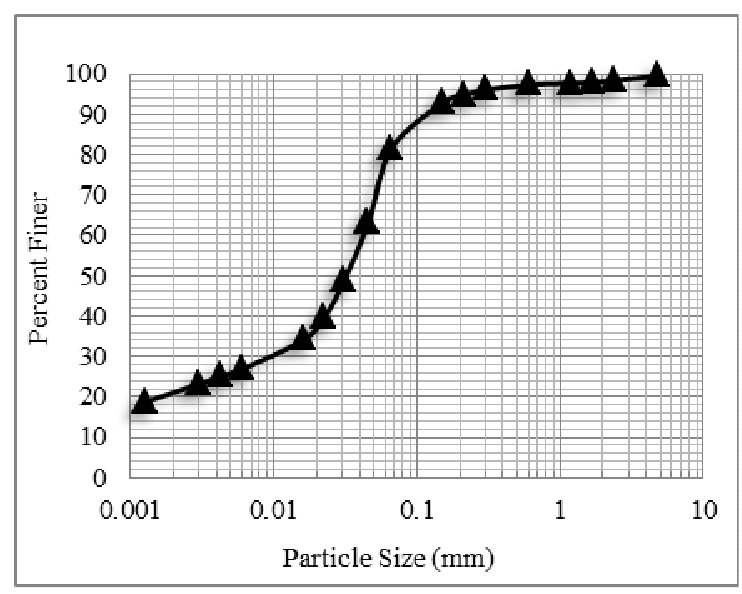

Figure 1. Particle size distribution curve of soil.

Textural Classification:

Clay Size $(<0.005 \mathrm{~mm})=26 \%$

Silt Size $(0.005-0.05 \mathrm{~mm})=40 \%$

Sand $(0.05-2.0 \mathrm{~mm})=32 \%$

Gravel $(>2 \mathrm{~mm})=2 \%$

\subsection{Jute}

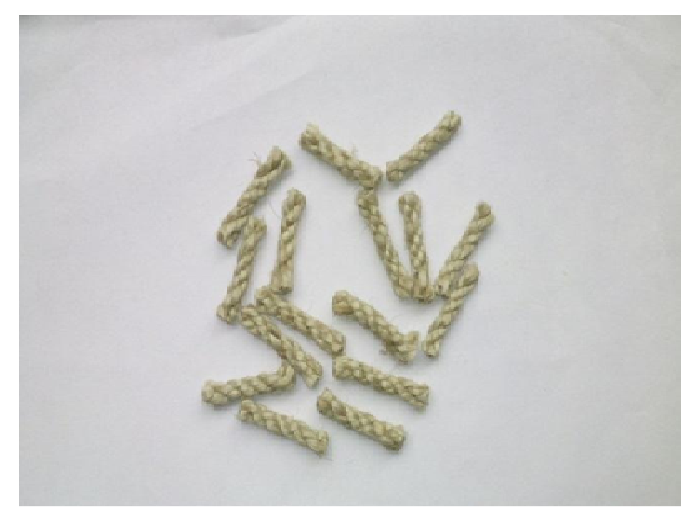

Figure 2. View of jute fiber ( $D=4 \mathrm{~mm}, L=30 \mathrm{~mm}$ ). 
The jute fiber used was procured from the local market. The diameter of the thread was $4 \mathrm{~mm}$ and $8 \mathrm{~mm}$ and length was $15 \mathrm{~mm}$ and $30 \mathrm{~mm}$. These fibers were generally available in the threaded form. These were mechanically woven fibers with very fine threads. The physical appearance of jute thread is shown in Figure 2. Jute industry is one of the oldest industries in Bangladesh, has traditionally been used for packaging. However its versatility is coming to light now after the world had started looking for natural options to save the environment. Jute is a coarse natural hast fiber. The major components of jute fiber are shown in Table 2.

Table 2. Properties and constituents of jute (after Aggarwal and Sharma, 2011)

\begin{tabular}{ll}
\hline Color & Yellowish brown \\
Specific Gravity $\left(\mathrm{G}_{\mathrm{s}}\right)$ & 1.12 \\
Diameter Used $(\mathrm{mm})$ & 4 and 8 \\
Length Used $(\mathrm{mm})$ & 15 and 30 \\
Hoiocelluiose $(\%)$ & $83-87$ \\
Lignin (\%) & $12-14$ \\
Wax (\%) & 0.4 to 0.81 \\
Ash (\%) & 0.5 to 1.04 \\
Nitrogen (\%) & 0.4 \\
\hline
\end{tabular}

\subsection{Bitumen}

Bitumen was used for coating the jute fiber to protect them from microbial attack \& degradation. Bitumen coating was done in the hot state at a temperature of $220^{\circ} \mathrm{C}$.

Grade and some of the other properties of bitumen are tabulated in Table 3.

Table 3. Properties of bitumen.

\begin{tabular}{ll}
\hline Grade & $80-100$ \\
Softening Point $\left({ }^{\circ} \mathrm{C}\right)$ & 52 \\
Flash Point $\left({ }^{\circ} \mathrm{C}\right)$ & 290 \\
Fire Point $\left({ }^{\circ} \mathrm{C}\right)$ & 310 \\
Specific Gravity $\left(\mathrm{G}_{\mathrm{B}}\right)$ & 1.02 \\
\hline
\end{tabular}

\section{Experimental Program}

A series of proctor compaction tests and California
Bearing Ratio tests have been carried out on soil mixed with jute fiber. The detailed procedure and results are as under.

\subsection{Proctor Compaction Test}

To assess maximum dry density (MDD) and optimum moisture content (OMC) Modified Proctor test is performed as per ASTMD-1557.

The jute fiber purchased from the market in diameter of 4 $\mathrm{mm}$ and $8 \mathrm{~mm}$ had been cut in the pieces of length nearly $1 \mathrm{~m}$ These pieces of the jute were coated with bitumen in order to protect it from microbial attack \& degradation. To coat the bitumen over jute fiber, bitumen was heated up to a temperature of nearly $220^{\circ} \mathrm{C}$. The thread of jute was dipped in it for about 2 to 3 second \& extra bitumen was streamed off with the help of fork. The pieces in the way were left for cooling of 24 hour. After 24 hour the threads were further cut in the small pieces of length equal to $15 \mathrm{~mm}$ and $30 \mathrm{~mm}$.

A series of modified proctor tests were carried out on the soil sample with $0.3 \%$ to $1.2 \%$ by weight of jute fiber coated with bitumen. While adding the jute fiber coated with bitumen in the soil mass, appropriate correction was applied to cater for the amount of bitumen.

From the result of modified proctor test it was observed that inclusion of jute fiber reduces the maximum dry density and increases the optimum moisture content for each length and diameter of jute fiber.

\subsection{California Bearing Ratio Test}

A series of California Bearing Ratio (CBR) tests were performed on the soil without jute fiber reinforcement and with different proportion of jute fiber based on the modified proctor test results. The test was performed for all the combination of the lengths and diameters of jute fiber and percentage.

\section{Results and Discussions}

Results of jute fiber reinforced soil are compared with that of unreinforced soil in the following sections.

Table 4. CBR value of soil reinforced with jute fiber

\begin{tabular}{|c|c|c|c|c|c|}
\hline \multirow{2}{*}{$\begin{array}{l}\text { Fiber Length } \\
(\mathrm{mm})\end{array}$} & \multirow{2}{*}{$\begin{array}{l}\text { Percentage of Fiber } \\
\text { by Dry weight of Soil }\end{array}$} & \multicolumn{2}{|c|}{ Fiber Diameter 4 mm } & \multicolumn{2}{|c|}{ Fiber Diameter 8 mm } \\
\hline & & CBR Value (\%) & $\%$ increase in CBR Value & CBR Value (\%) & $\%$ increase in CBR Value \\
\hline \multirow{5}{*}{15} & $0 \%$ & 5.22 & - & 5.22 & - \\
\hline & $0.30 \%$ & 5.76 & 10.34 & 6.30 & 20.69 \\
\hline & $0.60 \%$ & 6.48 & 24.14 & 6.84 & 31.03 \\
\hline & $0.90 \%$ & 7.02 & 34.48 & 7.20 & 37.93 \\
\hline & $1.20 \%$ & 7.38 & 41.38 & 7.56 & 44.83 \\
\hline \multirow{5}{*}{30} & $0 \%$ & 5.22 & - & 5.22 & - \\
\hline & $0.30 \%$ & 7.02 & 34.48 & 7.38 & 41.38 \\
\hline & $0.60 \%$ & 7.92 & 51.72 & 8.82 & 68.97 \\
\hline & $0.90 \%$ & 8.46 & 62.07 & 9.96 & 90.80 \\
\hline & $1.2 \%$ & 9.36 & 79.31 & 10.56 & 102.30 \\
\hline
\end{tabular}




\subsection{Effect of Jute Content on the MDD and OMC}

The Proctor tests results obtained from the tests conducted on the soil sample without jute fiber and with different percentage of jute fiber for various aspect ratios are discussed as below:

It is observed that inclusion of jute fiber reduces the MDD and increases the $\mathrm{OMC}$.

With addition of $0.3 \%$ of jute fiber (aspect ratio $=3.75$, length $=15 \mathrm{~mm}$, diameter $=4 \mathrm{~mm})$ the maximum dry density reduces from $1.96 \mathrm{gm} . / \mathrm{cc}$ ( $0 \%$ jute content) to $1.92 \mathrm{gm} . / \mathrm{cc}$, whereas the optimum moisture content increases from $11.11 \%$ ( $0 \%$ jute content) to $11.19 \%$.

MDD reduces from $1.92 \mathrm{gm}$. /cc (aspect ratio $=3.75$, length $=15 \mathrm{~mm}$, diameter $=4 \mathrm{~mm}$ ) to $1.83 \mathrm{gm}$. $/ \mathrm{cc}$ (aspect ratio $=3.75$, length $=15 \mathrm{~mm}$, diameter $=4 \mathrm{~mm}$ ), whereas there is an increase in OMC from $11.19 \%$ to $14.28 \%$ with inclusion of $0.3 \%$ to $1.2 \%$ jute content in the subgrade soil.

Similar affects are observed for aspect ratio 1.875 (length $=15 \mathrm{~mm}$, diameter $=8 \mathrm{~mm}$ ), 7.50 (length $=30 \mathrm{~mm}$, diameter $=4 \mathrm{~mm}$ ) and 3.75 (length $=30 \mathrm{~mm}$, diameter $=8 \mathrm{~mm}$ ) (see Figure 3).

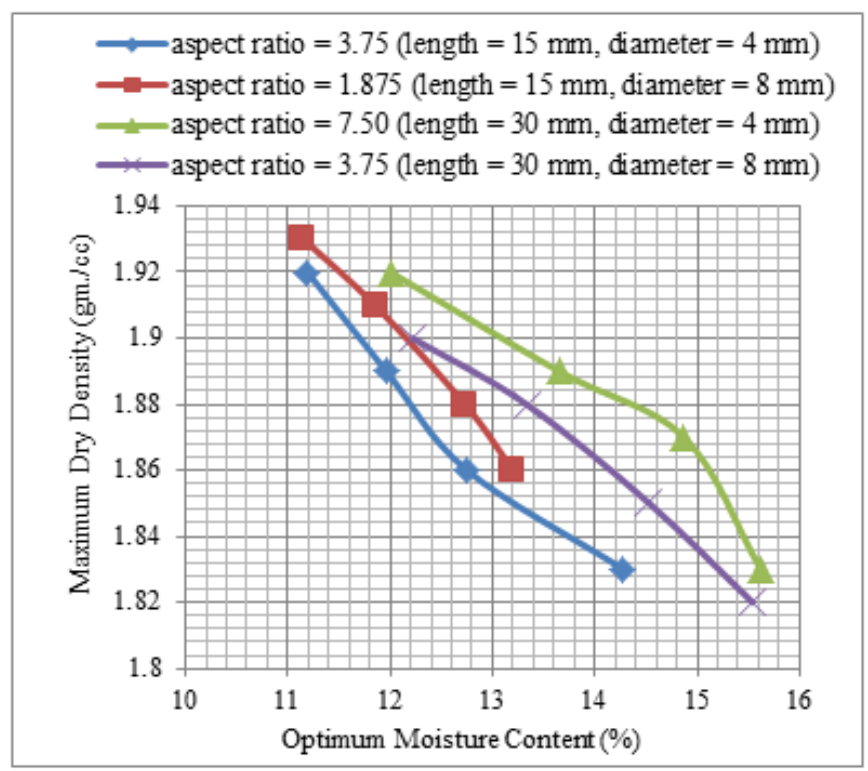

Figure 3. Proctor test results on soil mixed with different percentage of jute fiber for various aspect ratios.

\subsection{Effect of Aspect Ratio on CBR Value}

Table 4 presents the variation of CBR values with respect to aspect ratio (length/diameter ratio) of different percentage of jute fiber. The obtained results of Table 4 are plotted in Figure 4. It is observed from Figure 4 that when aspect ratio decreases the CBR value of soil increases for same percentage of jute content. For instance the CBR value of soil reinforced with jute fiber at $0.3 \%$ are $5.76 \%$ (aspect ratio $=$ 3.75 , length $=15 \mathrm{~mm}$, diameter $=4 \mathrm{~mm}$ ) and $6.30 \%$ (aspect ratio $=1.875$, length $=15 \mathrm{~mm}$, diameter $=8 \mathrm{~mm}$ ). Similarly the $\mathrm{CBR}$ values of soil reinforced with fiber contents of $0.6 \%$,
$0.9 \%$ and $1.2 \%$, increases from $7.92 \%, 8.46 \%$ and $9.36 \%$ to $8.82 \%, 9.96 \%$ and $10.56 \%$ respectively when aspect ratio decreases from 7.50 (length $=30 \mathrm{~mm}$, diameter $=4 \mathrm{~mm}$ ) to 3.75 (length $=30 \mathrm{~mm}$, diameter $=8 \mathrm{~mm}$ ).

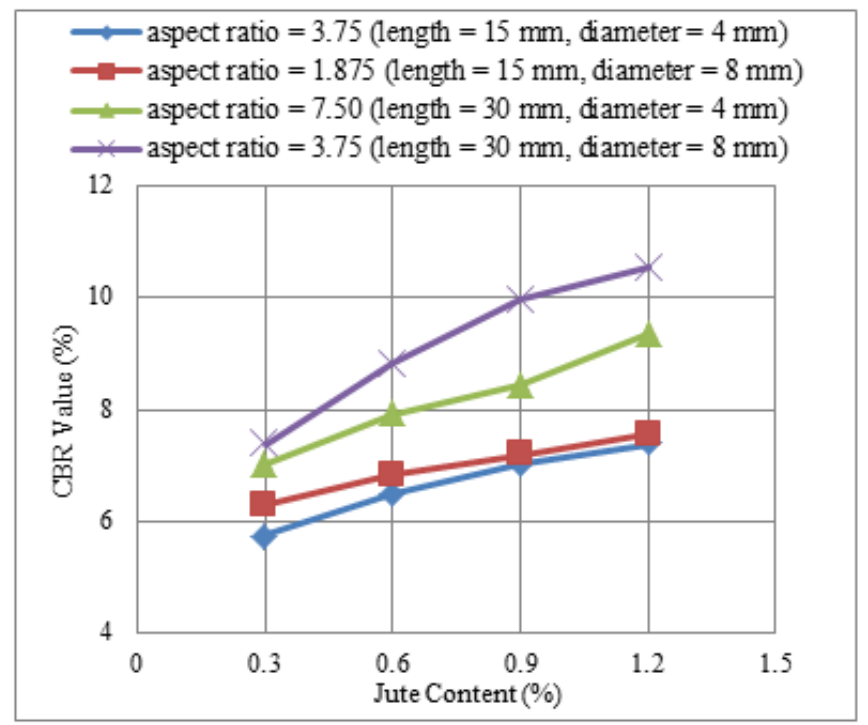

Figure 4. Variation of $C B R$ value with respect to jute content for different aspect ratios.

\section{Conclusions}

A series of CBR tests and Modified Proctor tests were conducted in the present study. The laboratory test results are presented and discussed in the sections above. From the above discussion the following conclusions can be drawn:

(i) Jute fiber reinforcement reduces the maximum dry density and increases the optimum moisture content of the subgrade soil for each aspect ratio.

(ii) The CBR value of soil increases when the aspect ratio decreases for same percentage of jute fiber.

\section{Acknowledgements}

The authors are thankful to the Head of Civil Engineering Department for providing laboratory facilities for conducting the tests. The help and support extended by the Laboratory Assistant of geotechnical engineering lab are gratefully acknowledged.

\section{References}

[1] Aggarwal, P. and Sharma, B., "Application of Jute Fiber in the Improvement of Subgrade Characteristics". International Journal on Transportation and Urban Development, 2011; 1(1), 56-58.

[2] Singh, H. P. and Bagra, M., "Improvement in CBR Value of Soil Reinforced with Jute Fiber". International Journal of Innovative Research in Science, Engineering and Technology, 2013; Vol. 2, Issue 8, 3447-3452. 
[3] Tera, S., and Reddy Jagannatha, H.P., "International Journal of Innovation, Management and Technology, 2011; 2 (3), 186191.

[4] Gray, D.H., and Ohashi, H., "Mechanics of fiber reinforcing in sand". Journal of Geotechnical Engineering, 1983; 112 (8), 335-353.

[5] Rao, P.J. "Jute Geotextile for improving the performance of Highway Embankment on soft Marine Soil", Proc. Nat. Sem, on Jute based Geotextiles, New Delhi, 1996.

[6] Singh, H.P., "Strength Characteristics of Soil Reinforced With Geosynthetic". International Journal of Earth Sciences and Engineering, 2011; 4 (6), 969-971.

[7] Sivakumar B., G.L., and Vasudevan, A.K., "Strength and Stiffness Response of Coir -Reinforced Tropical Soil”. Journal of Materials in Civil Engineering, 2008; 571-578.

[8] Singh, H.P., "Improvement in CBR Value of Soil Reinforced with Coir fiber". 3rd International Conference on Natural Polymer, (2012); held at Mahatma Gandhi University Kottayam, Kerala, India. 26-27 October Paper No118.

[9] Singh, H.P., Sharma, A., and Chanda, N., "Study of Strength Characteristics of Coir Reinforced Soil". International Conference on Advances in Material and Techniques for Infrastructure Development, 2011; held at NIT Calicut Kerala, India. Paper No.: G002 28-30 September.
[10] Lawton E.C., Khire, M.V. and Fox, N.S., "Reinforcement of soils by multioriented geosynthetic inclusion". Journal of Geotechnical Engineering, 1993; 119 (2), 257-275.

[11] Consoli, N.C., Montardo, J.P., Prietto, P.D.M. and Pasa, G.S., "Engineering behavior of sand reinforced with plastic waste". J. Geotech Geoenviron. Eng., 2002; 128 (6), 462-472.

[12] Ranjan, G., Vasan, R.M. and Charan, H.D., (1996), "Probabilistic analysis of randomly distributed fiberreinforced soil". Journal of Geotechnical Engineering, 1996; 122 (6), 419-426.

[13] Rao, A.S. Rao, K.V.N., Sabitha, G. and Suresti K., "Load deformation behavior of fiber-reinforced gravel beds overlying soft clay". A National Conference on Corrective Engineering Practices in Troublesome Soils, 2006; 187 -190.

[14] Michalowski, R.L. and Cerma'k, J., "Strength anisotropy of fiber reinforced sand". Comput. Geotech., 2002; 29 (4), 279299.

[15] Gray, D.H. and Al-Refeai, T., "Behaviour of fabric versus fibre-reinforccd sand". Journal of Geotechnical Engineering, $1986 ; 112$ (8), 804-820. 